[Aus dem Institut für Infectionskrankheiten in Berlin.] (Director: Geh. Med.-Rath Prof. Dr. R. Koch.)

\title{
Ueber einige praktische Anwendungen der Präcipitine in der Nahrungsmittelchemie.
}

$$
\text { Von }
$$

\section{Dr. Albert Schütze,} Assistenten am Institut.

Die Eiweissdifferenzirungsmethode mittels der TchistovitchBordet'schen Präcipitine, welche die sichere Unterscheidung von menschlichem und thierischem Eiweiss gestattet, hat in den letzten Jahren eine ausgedehnte experimentelle und praktische Bearbeitung gezeitigt. Bei der Bedeutung, welche die Anwendung der Präcipitine in der Nahrungsmittellehre zur Identificirung einer bestimmten Eiweissart durch Jess ${ }^{1}$, v. Rigler ${ }^{2}$ u. A. erlangt hat, schien der Versuch, auf biologischem Wege Eigelb in Margarine zum Nachweis zu bringen, gerechtfertigt, zumal diese Frage die Pharmaceuten in der letzten Zeit wiederholt beschäftigt hat. Dass es gelingt, die im Hühnerei enthaltenen, von einander verschiedenen nativen Eiweissstoffe zu differenziren, davon legen Zeugniss ab die Versuche von Ottolenghi ${ }^{3}$, der durch Einspritzungen von Eidotter in dem Serum von Kaninchen Substanzen erzeugte, welche die in der Injectionsflüssigkeit enthaltenen Eiweissstoffe zur Ausfällung brachte, während die in dem Eiereiweiss vorhandenen Albumine und Globuline durch das Serum solcher Kaninchen nicht präcipitirt wurden. Ottolenghi u. Uhlenhuth ${ }^{4}$, welcher etwa ein halbes

${ }^{1}$ Berliner thierärztl. Wochenschrift. 17. Oct. 1901. 1902, Nr. 46. 1903, Nr.5 u. 23.

- Oesterreich. Chemikerzeitung. 1902. Nr. 5.

3 Estratto dagli Atti della Accademia dei Fisio critici. Giena 12. Juli 1902. Serie 4. Vol. XIV.

4 Deutsche med. Wochenschrift. 1903. Nr. 5. S. 39. Vereinsbeilage. 
Jahr später zu demselben Resultat gelangte, dass die in dem Eigelb und Eiweiss vorkommenden Substanzen sich auf diesem biologischen. Wege von einander unterseheiden lassen, haben dann dieses Verfahren zum Nachweis von Eigelb in der Nahrungsmittelchemie in Vorschlag gebracht.

In einem auf dem 5.. Internationalen Congresse für angewandte Chemie gehaltenen Vortrage, welcher die Frage des Nachweises von Eigelb in Margarine behandelt, hat nun G. Fendler über diesbezügliche Versuche, welche er im pharmaceutischen Institut der hiesigen Universität angestellt hat, eingehend berichtet. Bekanntlich sind nämlich in jüngster Zeit verschiedene, durch Patentrerleihung geschützte Verfahren ausgearbeitet worden, welche den Zweck verfolgten, auf die künstliche Butter, die Margarine, die werthvollen Eigenschaften der Naturbutter, welche im Brärnen, Schäumen und im Ausbleiben des Spritzens beim Braten bestehen, zu übertragen. Eines dieser Verfahren, welches diesem Ziele am nächsten kommt, ist dasjenige von Bernegau, welches in dem Zusatz von Eigelb und Zucker besteht, der aber deswegen eigentlich überflüssig ist, weil schon der mit der Milch hinzugefügte Milchzucker ausreicht, um zusammen mit dem Eigelb Bräunen und Schäumen hervorzurufen. Wāhrend ursprünglich die Quantität des hierzu verwendeten Eigelbes bis $\mathrm{zu} 10$ Procent betrug, hat sich jetzt herausgestellt, dass durch eine so beträchtliche Menge die Haltbarkeit der Margarine ungünstig beeinflusst wird, und dass ein Zusatz von 0.5 bis 1.0 Procent ausreicht; um den beabsichtigten Erfolg zu erzielen. Das Bestreben Fendler's war nun darauf gerichtet, eine Methode auszuarbeiten, welche die Anwesenheit einer so kleinen Menge natürlichen Eigelbes in der Margarine sicher gestattete, da auch das Verfahren von Mecke ${ }^{2}$ den einwandsfreien Nachweis eines geringen Zusatzes von 0.5 bis 1.0 Procent nicht zuliess. Dieser Autor war so vorgegangen, dass er $100 \mathrm{grm}$ Margarine, welche bei $45^{\circ}$ geschmolzen waren, mit $50^{\mathrm{eem}} 1$ procent. Kochsalzlosung ausschüttelte, dieselbe durch Petroläther von ihrem Fettgehait befreite, mit Aluminiumbydroxyd schüttelte, filtrirte und das Filtrat mittels Wassers auf das 6 fache Volumen verdünnte. Er erhielt dann eine flockige Ausscheidung von Vitellin, welches dadurch ausgezeichnet ist, dass es nur in Kochsalzlösung von bestimmter Zusammensetzung, nicht aber in Wasser löslich ist. Fendler, welcher die Zweckmässigkeit dieser Methode für diejenigen Fälle, in welchen es sich um die Feststellung concentrirter Eigelblösung handelt, anerkennt, konnte bald die Beobachtung machen, dass durch das Aluminiumbydroxyd eine beträchtliche Menge des Vitellins Heft 21.

${ }^{1}$ Zeitschrift für Ontersuchung der Nahrungs- u. Genussmittel. 1. Novbr. 1903.

${ }^{2}$ Zeitschrift für öffentl. Chemie. 1899. Bd. V. S. 231.

Zeitschr, f. HYgiene, XLVII. 
gefällt und damit dem Nachweise entzogen wurde. Er betrachtete es daher als seine Aufgabe, Reactionen herrorzurufen, welche als charakteristisch für das Vitellin angesehen werden mussten. Anfangs hatte es den Anschein, dass es möglich wäre, durch Ueberschichten einer 25 procentigen Salpetersäure Erscheinungen im Reagensglase auszulösen, welche geeignet waren, eigelbhaltige von eigelbfreier und eiweisshaltiger Margarine zu unterscheiden. Indessen sollte es sich später zeigen, dass Concentrationsverhältnisse beim Ausfall dieser Reactionen, deren Deutung ausserdem in - Folge anderer Zusätze zur Margarine zu Täuschungen führen kann, eine -grosse Rolle spielen. Eine andere Methode des Eigelbnachweises, welche darin besteht, dass $10^{\mathrm{com}}$ der Margarineausschüttelung mit $1^{\mathrm{cm}} 1$ procent. Schwefelsäure in einem Reagensglase kurze Zeit zum Sieden erhitzt, abgekühlt und mit $2^{\mathrm{cm}}$ Aether einige Minuten kräftig durchgeschüttelt werden, ist zwar sehr scharf, insofern sie das Vorhandensein von Eigelb anzeigt, wenn die Aetherschicht eine gelbe Färbung angenommen hat, tritt jedoch auch bei Margarinearten auf, welche wasserlösliche Farbstoffe enthalten, so dass der positive Ausfall der Reaction keine absolut sichere Gewähr für die Anwesenheit von Eigelb bietet. Auf Grund praktischer - Tersuche, welche Fendler mit 11 Margarineproben von bekannter Zusammensetzung angestellt hat, hält dieser Autor es für das Zweckmässigste, folgendes Verfahren einzuschlagen: Nachdem die als Vorprüfungen zu betrachtenden Reactionen mit rauchender Salpetersäure und auf das Vorhandensein von Eigelbfarbstoff positiv ausgefallen waren, wurde hieran das Dialysirverfahren angeschlossen. Maassgebend für die Fendler'sche -Methode war die Erfahrung, dass das Vitellin sich in Kochsalzlösungen und nicht in Wasser löst, eine Eigenschaft, welche die übrigen, als Zusåtze für Margarine in Betracht kommenden Eiweissstoffe, wie Eieralbumin, Kaseïn, Pflanzeneiweiss, nicht besitzen. Es werden daher nach der Vorschrift von Fendler $50^{\mathrm{ccm}}$ der klaren, zu prüfenden Flüssigkeit in einen gut ausgewaschenen, noch feuchten Dialysatorschlauch gefült, welcher in ein grosses Gefäss mit Wasser gehängt wird. Zeigt die Flüssigkeit nach 5 bis 6 Stunden eine deutliche Trübung, welche nach Zusatz von Kochsalz bis zum Wiedereintritt einer vollständigen Klarheit verschwindet, so ist hiermit der Nachweis von Eigelb geführt.

Es liegt nicht im Rahmen unseres Arbeitsgebietes und kann nicht Aufgabe dieser Mittheilung sein, eine Nachprüfung und kritische Besprechung dieses ron Fendler angegebenen Verfahrens, welche den Fachgenossen überlassen bleiben muss, vorzunehmen. Für uns kam es nur darauf an, zu entscheiden, $o b$ es mit Hülfe der Eingangs erörterten biologischen Methode, also mittels der Präcipitinreaction, gelingt, den geringen Eigelbzusatz von 0.5 bis 1.0 Procent in der Margarine, dessen 
Nachweis zu vorstehenden chemischen Untersuchungen den Anlass gegeben hatte, mit Sicherheit festzustellen. Es schien dies um so aussichtsroller $z \mathfrak{u}$ sein, als wir ja wissen, dass geringe Beimengungen einer minderwerthigen Fleischart, z. B. vom Pferd zu Rinderschabefleisch darch Hinzafügung des Serums eines mehrere Thale mit Injectionen von Pferdeserum behandelten Kaninchens zu einem aus dem zu prüfenden Fleischmaterial bereiteten und klar filtrirten. Auszug nachgewiesen werden können. Ist die Reaction positir, so zeigt sich dies bekanntlich dareh die Bildung eines deutlichen Niederschlages an. Die Versuchsanordnung für die uns interessirende Frage war nun von selbst gegeben: Wir injicirten, um ein wirksames Eidotterantiserum zu erzielen; einer Anzahl grosser Kaninchen in Abständen von 3 bis 4 Tagen subcutan je 6 bis $10^{\mathrm{cem}}$ frischen, in sterilen Gläsern mit einem Glasstab zu einer leicht flüssigen Menge geschlagenen Hühnereigelbs und setzten diese Einspritzungen, welche gut vertragen wurden, so lange fort, bis die Thiere im Verlaufe von etwa 4 Wochen $50^{\mathrm{ccm}}$ dieses genuinen Eigelbs erhalten hatten. 6 Tage nach der letzten Injection wurden die Kaninchen entblutet, und das abgeschiedene Serum ohne Zusatz von Conservirnngsmitteln im Eisschrank aufbewahrt. Bevor wir jedoch zur Untersuchung der Margarine auf das Vorhandensein von Eigelb übergingen, war es nothwendig, das Serum unserer Versuchskaninchen auf seine präcipitirende Eigenschaft zu prüfen, zumal wir uns gelegentlich unserer forensischen Studien davon haben überzeugen können, dass die Sera mancher Kaninchen trotz einer mehrere Monate hindurch fortgeführten Behandlung mit subcutanen Injectionen von Blut- oder Milcheiweiss in Ermangelung passender Receptoren im Organismus die Fāhigkeit der Antikörperbildung vermissen liessen. Wir vermischten also je $0.1,0.5$ und $1.0^{\text {cem }}$ von dem Serum unserer mit Eigelb behandelten Kaninchen mit $5^{\mathrm{ccm}}$ einer in einem Verhältniss von 1:40 sterilen Wassers bereiteten Lösung von gat geschlagenem Hühnereigelb, und konnten nach 1 stündigem Stehen der Reagensgläschen im Brütschrank bei $37^{\circ}$ in allen Proben einen in seiner Stärke der Menge des jeweilig hinzugefügten Serums entsprechenden Niederschlag wahrnehmen, welcher weder nach Zusatz der gleichen Dosis von normalem Kaninchenserum, noch nach Vermischung mit $5 \mathrm{ccm}$ einer in demselben Verhältniss hergestellten Eiereiweisslösung eintrat. Erst ein längeres, $11 / 2$ - bis 2 stündiges Aufbewahren der Reagensröhrchen bei $37^{\circ}$ hatte die Bildung einer, aber bei Weitem geringeren Ausfällung der Eiereiweissstoffe durch das Antidotterserum zur Folge, worauf schon Uhlenhuth ${ }^{1}$ aufmerksam gemacht hat. Um nun zu

${ }^{1}$ Deutsche med. Wochenschrift. 1903. Nr. 5. S. 39. Vereinsbeilage. 
entscheiden, ob so geringe Mengen von 0.5 bis 1.0 Procent, wie diese als Zusatz. zum Eigelb von Fendler in seiner oben citirten Arbeit angegeben worden sind, sich mit Hülfe des biologischen Verfahrens nachweisen lassen, setzten wir in zwei Portionen, mit der Pipette abgemessen 0.25 bezw. $0.5^{\mathrm{com}}$ geschlagenen Hühnereigelbs in zwei Spitzgläser zu je $50^{\mathrm{cem}}$ einer im Wasserbade bei $45^{\circ}$ zum Schmelzen gebrachten eigelbfreien Margarine hinzu.. Nach einigen Stunden wurde, nachdem sich die Caseine am Boden der Spitzgläser abgesetzt hatte, von der. Oberfläche der geschmolzenen Margarine abpipettirt, und je $5^{\mathrm{com}}$ dieser klaren, goldgelhen Flüssigkeit in eine Anzahl Reagensröhrchen gefüllt. Ein Theil der Gläschen, von welchen ein jedes mithin 0.5 bezw. 1.0 Procent Eigelb suspendirt enthielt, wurde nun mit $0 \cdot 5$ bezw. $1 \cdot 0 \mathrm{~cm}$ unseres Eidotterantiserums beschickt, und gleichzeitig wurden Controlröhrchen mit der gleichen Dosis normalen Kaninchenserums angesetzt. Um eine möglichst innige Vermischung mit der fetthaltigen Margarine und dem Serum zu erzielen, wurde der Inhalt in den Reagensgläschen kräftig durchgèschüttelt. Dann wurden dieselben zusammen mit einigen Röhrchen, welche wir mit $5^{\mathrm{ccm}}$ der gleichen eigelbhaltigen verflüssigten Margarine allein beschickten, um eine auch ohne Serumzusatz etwa spontan auftretende Trübung wahrnehmen zu können, auf die Dauer von $1 / 2$ bis höchstens 1 Stunde bei einer Brütschranktemperatur von $45^{\circ}$ aufbewahrt. Will man die auf ihren Eigelbgehalt zu untersuchende, in Wasser unlösliche, geschmolzene Margarine verdünnen, so empfiehlt es sich, hierzu eir indifferentes Oel, z. B. das officinelle Olivenöl, anzuwenden. Wir gingen dann so vor, dass wir zu $1^{\mathrm{com}}$ der verflüssigten Margarine $9^{\mathrm{ccm}}$ dieses Oeles hinzufügten, kräftig umschüttelten und $5^{\mathrm{ccm}}$ hiervon mit dem Dotterantiserum in der oben beschriebenen Weise vermischten. Nach Ablauf ron 45 bis 60 Minuten wurde in den mit dem Immunserum, aber nur in den mit diesem versetzten Röhrchen eine unverkennbare Präcipitinbildung beobachtet, bestehend in einer dichten, flockigen, ringförmigen Trübung, welche am deutlichsten beim Schräghalten der Röhrchen an der Grenze zwischen dem die Reagensglaskuppe einnehmenden, specifisch schwereren Serum und der darüber stehenden Margarineprobe wahrzunehmen war. Alle übrigen, also auch die mit normalem Serum versetzten Röhrchen waren vollkommen klar geblieben. Um nun die Brauchbarkeit dieses Verfahrens an einem grösseren Material zu controliren, entnahm ich aus verschiedenen Geschäften je sechs als eigelbfreie, und die gleiche Anzahl als eigelbhaltige Margarine verkaufte Proben, und konnte thatsächlich in diesen Fällen das Fehlen oder Vorhandensein von Eigelb in einwandsfreier Weise mittels der biologischen Methode entscheiden, welche sich daher als ein einfaches, bequemes und zurerlässiges Mittel gezeigt hat, um selbst so geringe Mengen von Eigelb, wie sie nach An- 
gabe der Fabriken den von uns untersuchten Proben hinzugefügt waren, in der Margarine festzustellen. Es sei daher dieses Verfahren in denjenigen Fällen, in welchen es sich um die Beantwortung der Frage handelt, $o b$ die zu untersuchende Margarine Eigelb enthält oder nicht, empfohlen. Es braucht nicht erst darauf hingewiesen zu werden, dass es nicht gelingt, mit Hülfe dieses Verfahrens die A rt der Verfälschungen, welche in der Substitution minderwerthiger wasserlöslicher Farbstoffe besteht, durch welche die natürliche Farbe des Eigelbs vorgetäuscht werden soll, festzustellen, da es sich ja hierbei eben um die Anwendung einer biologischen Eiweissdifferenzirungsmethode, welche natives Eiweiss : mit Sicherheit zu .identificiren gestattet, handelt. Aufgabe der chemischen Untersuchung wird es sein müssen, zu bestimmen, ob beispielsweise Orlean, Safran; Curcuma oder andere Farbstoffe an Stelle des Eigelbs Verwendung gefunden haben.

In denjenigen Fällen, in welchen es sich um den Nachweis von Casernen in Butter und Margarine handelt', empfiehlt es sich nach unseren Versuchen, Kaninchen mit mehrere Male wiederholten Injectionen von Kubmilch. zu behandeln. Das Serum solcher Thiere giebt dann in einer caseInhaltigen, aus Butter oder Margarine bereiteten Lösung einen deutlichen Niederschlag.

Es ist nun ohne Weiteres klar, dass auch andere für den Bèdarf in Betracht kommende Ernährungsmittel, zu deren Bereitung gesetzmässig Eigelb verwendet werden soll, mittels der Präcipitine auf das Vorhandensein von genuinem Eigelb untersucht werden können. Ein beliebter und im Kleinhandel viel gebrauchter Artikel sind die Eiernudeln, zu deren Herstellung, wie die Erfahrung lebrt, statt des vorgeschriebenen Eigelbs oftmals Anilinfarbstoffe herangezogen werden: Zumal gerade in der letzten Zeit die Untersuchung. von Eiernudeln die chemischen Laboratorien mehrfach beschäftigt hat, hielt ich es für lohnend, nachzusehen, ob das biologische Verfahren auch diese geringen Mengen von Eigelb, welche zur Herstellung ron' Eiernudeln verwendet werden, sicher zum Nachweis zu. bringen vermag. Ich besorgte mir daher wiederum aus verschiedenen Geschäften mehrere, insgesammt 12 Proben Eiernudeln. Von diesen wurden je $5^{\text {grm }}$ abgewogen und in einem sterilen Porzellanmörser unter Zusatz von $25 \mathrm{~cm}$ phys. Kochsalzlösung mit einem Pistill gründlich zerkleinert. Das Gemisch wurde dann in ein Erlenmeyer'sches Kölbehen gefüllt, im Schüttelapparat etwa $1 / 2$ Stunde tüchtig durchgeschüttelt, die Flüssigkeit

'Vgl. bierzu: G. Fendler, „Ueber die Bestimmung ron Eiweissstoffen, Milchzucker und Salzen in Butter und Margarine". Zeitschrift für Untersuchung der Nahrungs- u. Genussmittel. 1. November 1903. Hft. 21. 
abpipettirt und in spitzen Röhrchen centrifugirt. Von der oben stehenden klaren, gelblich gefärbten Flüssigkeit wurden nun je $5^{\mathrm{cem}}$ in Reagensgläschen gegossen, welche mit 0.5 bezw. $1.0^{\mathrm{cm}}$ unseres, auf oben geschilderte Weise gewonnenen Eidotterantiserums versetzt wurden. Es stellte sich hierbei heraus, dass von den untersuchten zwölf verschiedenen Probeu in zehn Fällen durch eine nach 1 stündigem Verweilen der Röhrchen bei $37^{\circ}$ eingetretene Präcipitinbildung der sichere Nachweis von Eigelb in den Eiernudeln geführt werden konnte, während in zwei Proben trotz längerer Aufbewahrung der Gläschen im Brütschrank, ebenso wie in den mit normalem Serum versetzten, und das zu prüfende Material allein enthaltenden Röhrchen kein Niederschlag wahrgenommen werden konnte. Es war also hierdurch bewiesen, dass diese beiden Portionen eigelbfrei waren, und mithin zur Herstellung dieser zwei Sorten von Eiernudeln kein Eigelb verwendet worden war. Die nun einsetzende chemische Untersuchung, deren Resultat. hiermit in vollem Einklange stand, ergab, dass an Stelle des Eigelbs in dem einen Falle Safran, in dem anderen Curcuma zur künstlichen Erzeugung des Eigelbfarbstoffes benutzt worden war.

Wenn es nun auch nicht möglich ist, mittels der Präcipitine die Art der an Stelle des Eigelbs vorgenommenen Verfälschung festzustellen, so gelingt es doch, mit Sicherheit das Vorhandensein oder Fehlen von Eigelb in dem zur Untersuchung vorliegenden"Material (Eiernudeln, Eiergraupen, Fierteigwaren, Eierkognak u. dergl.) durch den positiven oder negativen Ausfall der biologischen Reaction zu bestimmen. Es sei daher die Anwendung dieses Eidotterantiserums, namentlich für die gedachten. Zwecke, den Herren Sachrerständigen zur Nachachtung empfohlen.

Im Anschluss hieran möchte ich über eine Beobachtung kurz berichten, welche vielleicht einiges praktische Interesse beansprucht. Das Uebereinstimmende in fast allen Versuchen, welche die Erzielung eines Immunserums gegen Eiweiss zum Zweck haben, besteht, wie aus der Litteratur zur Genüge hervorgeht, darin, dass die gleiche Species, nämlich Kaninchen, hierzu verwendet werden, weil es sich gezeigt hat, dass gerade diese Thiere besonders geeignet sind, auf die Einverleibung von Eiweissstoffen in den Organismus mit der Bildung von Antikörpern in ihrem Serum zu reagiren, welche sich nach Vermischung desselben mit dem zur Einspritzung gewählten Material durch .Auftreten eines Niederschlages, d. h. durch Präcipitinbildung, im Reagensglase documentiren. $\mathrm{Da}$ es für praktisch-forensische Zwecke wünschenswerth ist, eine grössere Quantität von wirksamen Serum im Bedarfsfalle schnell zur Verfügung zu haben, so erschien der Versuch gerechtfertigt, grösseren Thieren subcutan entsprechend höhere Dosen des gleichen Eiweissmaterials zu injiciren und danach das Serum dieser Thiere auf seine 
präcipitirende Kraft zu prüfen. Von diesem Gedanken ausgehend, hatten Wassermann und Verfasser ${ }^{1}$ längere Zeit hindurch eine Ziege, Uhlenhuth ${ }^{2}$ ein Lamm und eine Ziege mit Einspritzungen von Menschenserum behandelt, und das Resultat dieser Experimente lehrte uns, dass es bei den genannten Thierarten auf diesem Wege nicht gelang, ein für gerichtsärtliche Zwecke geeignetes Serum zu erzielen.

Durch das freundliche Entgegenkommen des Hrn. Prof. A. Wassermann erhielt ich nun Gelegenheit, von Zeit zu Zeit einem ca. 6 Centner wiegenden Ballen, welchem zwecks Ausführung anderer Experimente in Zwischenräumen von 8 bis 10 Tagen 250 bis $300^{\mathrm{cem}}$ sterilen Pferdeserums subeutan 2 Monate hindurch injicirt wurden, aus der. Vena jugularis Blut zu entziehen und das abgeschiedene Serum auf seine Pferdeeiweiss fällende Eigenschaft hin zu untersuchen. Ich konnte nun die Wahrnehmung machen, dass nach Zusatz von $1 / 2{ }^{\mathrm{cem}}$ dieses Serums zu $5^{\mathrm{ccm}}$ einer durch destillirtes Wasser lackfarben gemachten dünnen Pferdeblutlōsung oder zu der gleichen Menge eines für die praktischen Zwecke in Betracht kommenden klar filtrirten Pferdefleischextractes bei $37^{\circ}$ innerhalb $1 / 2$ Stunde eine deatliche Trübung auftrat, welche sich zu einem unverkennbaren Niederschlag verdichtete und in den mit normalem Serum angestellten Controlröhrchen nicht zu beobachten war. Wir konnten weiterhin feststellen, dass nach Hinzufügung der gleichen Dosis von Serum des mit Pferdeeiweiss behandelten Bullen zu $5^{\text {cco }}$ eines aus Rinder- oder Schweinefleisch bereiteten klaren Auszuges innerhalb dieser Zeit keine Trübung sich bildete. Allerdings wurde eine geringe Ausfällung nach Vermischung von 0.5 bis $1.0^{\mathrm{ccm}}$ des zu prüfenden Serums mit $5^{\mathrm{ccm}}$ des Rindfleischextractes nach mehrstündigem Stehen der Reagensgläschen im Brütschrank, wenn auch in weit geringerem Maasse als in den mit derselben Menge versetzten, den Auszug aus dem Pferdefleisch enthaltenden Röhrchen beobachtet. Wir ersehen also aus diesem Versuch von Neuem, dass die Proben, um Täuschungen zu vermeiden, nicht über eine bestimmte Zeit hinaus, und zwar nicht länger als 1 Stunde bei $37^{\circ}$ belassen werden sollen aus Gründen, welche anderen Ortes $^{3}$ eingehend ausgeführt worden sind und Wassermann und Schütze zur Einführung einer genauen Werthbemessung der präcipitirenden Sera mittels der sogen. "Präcipitirungseinheiten" Veranlassung gaben, welche für die praktischen Zwecke der Erkennung der Pferdefleischverfälschung auch von Jess ${ }^{4}$ auf dem Boden

\footnotetext{
1 Berliner klin. Wochenschrift. 1901. Nr. 7. Anmerkung.

2 Deutsche med. Wochenschrift. 1902. Nr. 37.

3 Ebenda. 1903. Nr. 11.

- Berliner thierärztl. Wochenschrift. 1903. Nr. 23.
} 
152 Albert SchÜtze: Ałwendungen der Präcipitine o. $s$. w.

ausgedehnter Untersuchungen vollständig anerkannt und angenommen worden ist.

Jedenfalls mag der Hinweis gestattet sein, dass es gelungen ist, durch längere Zeit fortgeführte Behandlung eines Bullen mit subcutanen Injectionen von sterilem Pferdeserum ein Serum zu erzielen, welches den Anforderungen, die wir an ein solches, für praktisch-veterinärärztliche Zwecke brauchbares Serum stellen müssen, vollkommen genügt. Sollte es sich verlohnen, und sollte das biologische Verfahren in der Veterinärmedicin eine solche Bedeutung erlangen, dass es häufiger zum Nachweis von Pferdefleischverfälschungen herangezogen zu werden verdient, so. dürfte es vielleicht empfehlenswerth sein; für diese Untersuchungen einen mittelgrossen Bullen einzustellen, demselben etwa 1 Monat hindurch $2 \mathrm{Mal}$ wöchentlich je $150^{\mathrm{ccm}}$ sterilen Pferdeserums auf ein Mal subcutan zu injiciren und diese Einspritzungen von 150 bis $200 \mathrm{~cm}$ an jedem. 8. Tage zu wiederholen, um das Immunserum des Thieres annähernd auf der gleichen Höhe zu erhalten. Es wird auf diese Weise Gelegenheit. gegeben sein, jederzeit ein wirksames Serum in grösseren Quantitäten, als dies von Kaninchen gewonnen werden kann, durch einen einfachen Einstich in die Vena jugularis des Bullen zu erhalten, abgesehen davon, dass bei kleineren Thieren, welche ausserdem der Gefahr der Stallseuchen in höherem Grade als grössere Thiere ausgesetzt sind und erheblich leichter eingehen als diese, nach unseren Erfahrungen eine häufigereWiederholung der Injectionen angezeigt ist. 